\title{
Tas legemidler som foreskrevet?
}

\begin{abstract}
Sammendrag
Bakgrunn. Begrepet «etterlevelse» brukes for å beskrive hvorvidt legemidler tas som foreskrevet. Denne artikkelen omhandler hva som er kjent når det gjelder etterlevelse for noen sentrale legemiddelgrupper, hvilke faktorer som påvirker etterlevelsen, hvilke konsekvenser lav etterlevelse kan ha og hvordan den kan bedres.
\end{abstract}

Kunnskapsgrunnlag. Vi har gått gjennom et utvalg studier av etterlevelse når det gjelder sju legemiddelgrupper: antidiabetika, antiepileptika, antihypertensiver, statiner, psykofarmaka, antibiotika og analgetika.

Resultater. Ved bruk av antidiabetika varierte andelen pasienter med høy etterlevelse mellom $31 \%$ og $80 \%$ i de ulike studiene. For antiepileptika var de tilsvarende tallene $61-74 \%$, for antihypertensiver $23-73 \%$, for statiner $25-44 \%$, for psykofarmaka $21-80 \%$, for antibiotika $41-70 \%$ og for analgetika 41-53\%. Etterlevelsen var generelt sett fallende over tid. Ved alvorlige sykdommer førte nedsatt etterlevelse til symptomforverring, med økt risiko for sykehusinnleggelse og $d ø d$. Det er vist at dosering én gang daglig gir høyere etterlevelse enn dosering flere ganger om dagen. Komplekse behandlingsregimer, depresjon, nedsatt kognitiv funksjon, bivirkninger og utilstrekkelig oppfølging gir lavere etterlevelse.

Fortolkning. Det er viktig å oppnå høy etterlevelse, ikke minst ved alvorlige sykdommer. For å få høyere etterlevelse må man identifisere de pasientene som har lav etterlevelse, forsøke å forstå hvorfor pasienten ikke tar legemidlet og om det er praktiske problemer forbundet med inntaket. God kommunikasjon mellom pasient og lege er en nøkkelfaktor.

Artikkelen er basert på en studentoppgave ved Det medisinske fakultet, Norges teknisk-naturvitenskapelige universitet (1).

Ingrid Hov og Margunn Bjartnes har bidratt like mye til denne artikkelen.
Ingrid Hov

Margunn Bjartnes

Lars Slørdal

Olav Spigset

olav.spigset@legemidler.no

Institutt for laboratoriemedisin,

barne- og kvinnesykdommer

Norges teknisk-naturvitenskapelige universitet og

Avdeling for klinisk farmakologi

St. Olavs hospital

For å beskrive i hvilken grad en pasient henter ut et legemiddel på apoteket, tar det til riktig tid og i rett dose og eventuelt fullfører en behandling brukes begrepet «etterlevelse». På engelsk har man begrepene «compliance», «concordance» og «adherence» for å beskrive om en pasient tar et legemiddel som foreskrevet $(2,3)$. «Compliance» kan oversettes med føyelighet eller ettergivenhet. I dette begrepet ligger det at pasienten passivt følger legens ordre, det forutsetter dermed ikke noen allianse mellom lege og pasient. Tidligere ble «compliance» også brukt på norsk. «Concordance» kan oversettes med overensstemmelse, samstemmighet eller enighet, og «adherence» kan bety troskap, fastholdelse eller det å gi sin tilslutning til noe. Disse begrepene impliserer en mer aktiv tilslutning fra pasientens side og foretrekkes av mange, da de innebærer at legen og pasienten på et likeverdig grunnlag enes om behandlingen. De engelske begrepene er dermed ikke helt synonyme, men vektlegger ulike aspekter av samspillet mellom lege og pasient når det gjelder kommunikasjon, bestemmelsesmyndighet og behandlingsansvar.

Det finnes en rekke metoder for å måle etterlevelse (ramme 1). Alle har sine fordeler og ulemper, og det finnes ingen referansemetode. I mange studier uttrykkes graden av etterlevelse som tilgjengelighetsraten (medication possession ratio; MPR) for det aktuelle legemidlet. Dette er definert som antall dager legemidlet rekker til ut fra doseringen og totalmengden som er forskrevet, dividert på totalt antall kalenderdager studert, som oftest regnet mellom to reseptuttak fra apotek. Det finnes ingen standard som definerer hvor grensen bør gå mellom det man på den ene side kan beskrive som adekvat, god eller høy etterlevelse og det som på den annen side må regnes som mangelfull, dårlig eller lav etterlevelse. I de fleste studier er grenseverdien satt ved inntak av eller tilgang til $80 \%$ av legemiddeldosene. En alternativ måte er å beskrive graden av etterlevelse numerisk ved å bruke en skala fra $0 \%$ inntak av legemiddeldosene til (over) $100 \%$, uten å definere noen grenseverdi.

Målet med denne studien var å beskrive hva som er kjent når det gjelder graden av etterlevelse for noen sentrale legemiddelgrupper. Vi ønsket å kartlegge mulig påvirkning fra modifiserende faktorer, som alder, kjønn, sosial bakgrunn, sykdommens alvorlighetsgrad, legemiddeldosering, polyfarmasi og komorbiditet samt om det forelå dokumentasjon på at graden av etterlevelse kunne påvirke sykelighet og dødelighet. Legemiddelgruppene ble valgt for å belyse hvordan etterlevelsen påvirkes av faktorer som akutt versus kronisk sykdom, symptomfrie versus symptomgivende tilstander, primærprofylakse versus sekundærprofylakse og somatisk versus psykisk sykdom.

\section{Kunnskapsgrunnlag}

Studien er en litteraturgjennomgang der vi valgte å se nærmere på de sju legemiddelgruppene antidiabetika, antiepileptika, antihypertensiver, statiner, psykofarmaka, antibiotika og analgetika. Databasen PubMed ble brukt for å identifisere relevante artikler. Søket ble avgrenset til 15-årsperioden 1.1. 1995-31.12. 2009

Først ble Medical Subject Heading (MeSH)-termen «patient compliance» koblet sammen med hver av MeSH-termene «hypoglycemic agents», «anticonvulsants», «antihypertensive agents», «hydroxymethylglutaryl-coA reductase inhibitors», "antipsychotic agents», «antidepressive agents», «anti-bac-

\section{Hovedbudskap}

- Ved behandling av symptomfrie tilstander som hypertensjon og forhøyede kolesterolnivåer er etterlevelsen lavere enn ved behandling av tilstander som gir symptomer, som smertefulle sykdommer og infeksjonssykdommer

- Kompliserte behandlingsregimer, dosering mer enn én gang daglig, forekomst av bivirkninger og utilstrekkelig oppfølging er faktorer som reduserer etterlevelsen

- Ved alvorlige sykdommer er det viktig å oppnå høyest mulig etterlevelse 
terial agents» og «analgesics». Antall treff er vist $\mathrm{i}$ figur 1.

For å identifisere aktuelle studier for inklusjon, ble relevans først vurdert ut fra artikkeltittel av IH og MB, basert på følgende kriterier: Studier som ikke handlet om og presenterte data for etterlevelse i en undersøkt pasientpopulasjon ble ekskludert. Artikler som ikke var engelskspråklige ble ekskludert. For antibiotika (antibakterielle midler) ble artikler om tuberkulostatika ekskludert, og for analgetika ble artikler om sykdomsspesifikke legemidler (som triptaner ved migrene og aminosalisylsyrepreparater ved inflammatoriske tarmsykdommer) ekskludert. For blodtrykksmidler ble artikler om pulmonell hypertensjon og om forhøyet intraokulært trykk ekskludert.

I neste trinn ble de gjenværende artiklene (fig 1) vurdert ut fra informasjonen i sammendraget (abstraktet). For å bli inkludert måtte det være kvantifisert hvordan graden av etterlevelse ble påvirket av én eller flere av følgende faktorer: alder, kjønn, sosial bakgrunn, sykdommens alvorlighetsgrad, antall tabletter og/eller antall doseringstilfeller av legemidlet per døgn, samtidig bruk av andre legemidler, andre somatiske eller psykiske sykdommer samt oppfølgingstid.

De studiene som fortsatt var aktuelle, ble lest i fulltekst (fig 1). Basert på ovennevnte kriterier, samt på om det fantes informasjon om effekt av grad av etterlevelse på endepunkter som sykdomsforløp og sykehusinnleggelse, ble de studiene som ble vurdert som mest informative til sist inkludert $\mathrm{i}$ vår studie (e-tab 1) (4-25).

\section{Resultater}

\section{Antidiabetika}

Resultatene fra de fire inkluderte studiene (4-7) presenteres i detalj i e-tabell 1. Samtlige gjaldt bruk av perorale midler. Andelen med høy etterlevelse $\mathrm{i}$ de tre studiene der dette ble oppgitt, varierte mellom $31 \%$ og $80 \%$ (4-6). En mulig årsak til den store spredningen var at det i studien der man fant den laveste etterlevelsen, var et strengere krav til hva som ble definert som høy etterlevelse (4). I tillegg var observasjonstiden kortere, kun ett år, i studien med den største andelen pasienter med høy etterlevelse (6). I en tidligere oversiktsartikkel fant man etterlevelsestall på $60-85 \% \mathrm{i}$ et tidsperspektiv på inntil seks måneder (3). Dette tatt $\mathrm{i}$ betraktning stemmer etterlevelsestallene relativt godt overens.

Resultatene vedrørende effekten av kjønn, alder og komorbiditet var motstridende. Økende antall tabletter daglig var assosiert med fallende etterlevelse, og behandling med flere preparater ga lavere etterlevelse enn behandling med ett (5). I en tidligere oversiktsartikkel var det i stor grad liknende funn (3). I tillegg refereres det i oversiktsartikkelen til data som viser at pasienter med samtidig depresjon har lavere etterlevelse, og at dosering én gang daglig gir høyere etterlevelse enn dosering to ganger om dagen. I gjennomsnitt ble $79 \%$ av tablettene tatt som foreskrevet ved dosering én gang daglig, $66 \%$ ved dosering to ganger daglig og $38 \%$ ved dosering tre ganger daglig. Overgang fra to preparater til de samme stoffene gitt som et kombinasjonspreparat økte også etterlevel-

\section{Ramme 1}

\section{Metoder for å måle etterlevelse}

- Registrering av uttak av legemidler fra apotek

- Spørreskjemaer til pasienter

- Intervju med pasienter

- Føring av dagbok der pasienten registrerer sitt legemiddelinntak

- Telling av tabletter

- Elektronisk registrering av åpning av tablettglass

- Måling av legemiddelkonsentrasjonen i blod eller urin

sen, i en studie fra $71 \%$ til $87 \%$ (3). I én studie fant man at pasienter med lav etterlevelse hadde økt risiko for sykehusinnleggelse (oddsratio (OR) 1,58; $95 \%$ konfidensintervall (KI) 1,38-1,81) og død (OR 1,81; $95 \%$ KI $1,46-2,23)(6)$.

\section{Antiepileptika}

Resultatene fra de tre inkluderte studiene (8-10) presenteres i detalj i e-tabell 1. Andelen med høy etterlevelse varierte mellom $61 \%$ og $74 \%$. I én av studiene fant man at etterlevelsen var høyere hos dem som tok mer enn ett legemiddel for sin epilepsi (10). Etterlevelsen var lavere hos pasienter med andre sykdommer i tillegg (8).

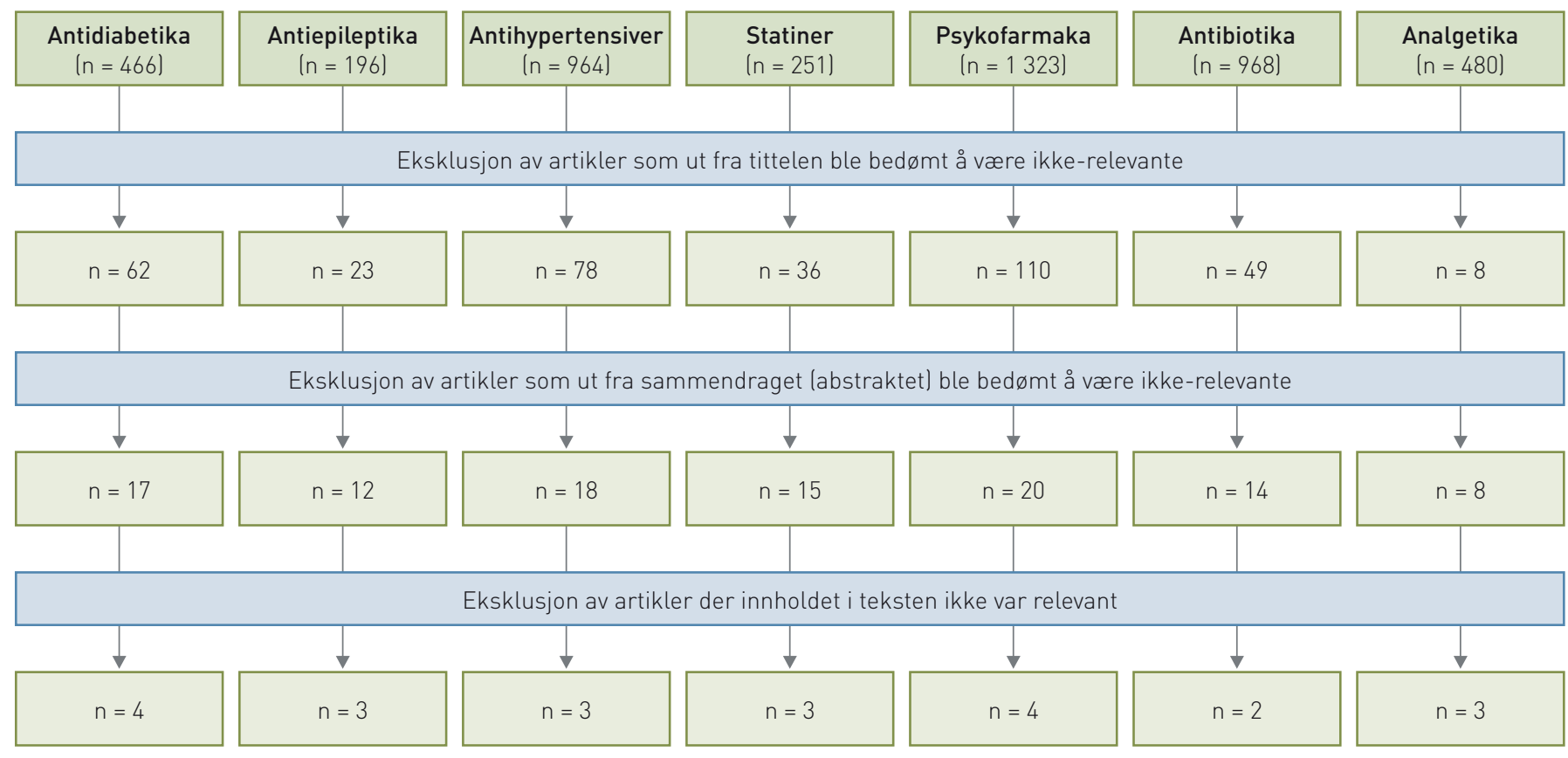

Figur 1 Flytdiagram som viser hvor mange studier som ble funnet ved søk i PubMed og hvor mange som ble ekskludert - først basert på tittel, deretter basert på sammendraget og til sist på hele artikkelen. I det første trinnet var det svært mange artikler som kunne ekskluderes fordi det var åpenbart at etterlevelse ikke var en sentral del av innholdet. Eksempler på dette er kliniske legemiddelutprøvninger, artikler som ikke var originalstudier og studier som var basert på teoretiske/matematiske modeller og ikke på reelle pasientpopulasjoner. Inklusjon i siste trinn var i hovedsak basert på en total vurdering av kvalitet, inklusive om det fantes informasjon om effekt på endepunkter som sykdomsforløp og sykehusinnleggelse. Se metodedelen for detaljer 
I to av studiene ble risikoen for sykehusinnleggelse undersøkt $(8,9)$. I den ene fant man en lett økt risiko (OR 1,11; $p=0,013$ ) for å bli innlagt ved lav etterlevelse (9), i den andre var risikoen nær fordoblet (relativ risiko (RR) 1,86 ; $95 \%$ KI 1,84-1,88) (8). I den siste studien var risikoen for død over tre ganger høyere hos pasienter med lav etterlevelse enn hos pasienter høy etterlevelse (hasardratio 3,$32 ; 95 \%$ KI 3,11-3,54) (8).

\section{Antihypertensiver}

Resultatene fra de tre inkluderte studiene (11-13) presenteres i detalj i e-tabell 1. Andelen med høy etterlevelse varierte mellom $23 \%$ og $73 \%$. Den viktigste årsaken til den store variasjonen er trolig at ulike populasjoner ble undersøkt. I studien med lavest etterlevelse deltok pasienter innenfor det amerikanske Medicaid-systemet, som er en helseforsikringsordning for sosialt og økonomisk særlig vanskeligstilte (11), mens det var tidligere ansatte $\mathrm{i}$ det amerikanske forsvaret som deltok i studien med høyest etterlevelse (12). I sistnevnte studie fant man også at jo mer aktiv og involvert pasienten var i egen legemiddelbehandling, desto høyere var etterlevelsen (12). Det var ingen konsistent effekt av alder eller kjønn.

\section{Statiner}

Resultatene fra de tre inkluderte studiene (14-16) presenteres i detalj i e-tabell 1. Andelen med høy etterlevelse varierte mellom $25 \%$ $\operatorname{og} 44 \%$. En viktig forklaring på disse forskjellene er trolig ulik oppfølgingstid. I alle studiene var etterlevelsen fallende med tiden.

Det var ingen konsistent effekt av alder eller kjønn. Etterlevelsen var lavere hos dem som fikk primærprofylakse enn hos dem som hadde manifest koronarsykdom (14, 15). Flere doser daglig var forbundet med lavere etterlevelse (16). Av tilleggssykdommer var depresjon og demens assosiert med lavere etterlevelse, mens hypertensjon, hjerneslag, hjertesvikt og diabetes var assosiert med høyere (15).

\section{Psykofarmaka}

Resultatene fra de fire inkluderte studiene (17-20) presenteres i detalj i e-tabell 1. To av dem inkluderte pasienter med depresjon $(17,18)$, én inkluderte pasienter med schizofreni (18), mens deltakerne i den siste var pasienter med psykisk sykdom uavhengig av diagnose (20). Andelen med høy etterlevelse var høy, 67-80\%, i tre studier (17, $18,20)$, mens den var kun $21 \%$ i den fjerde (19). I den ene av de studiene der man fant høy etterlevelse, visste imidlertid pasientene at de ble undersøkt med tanke på legemiddelinntak (17), og i den andre brukte man spørreskjemaer og journaldata (18), noe som kan overestimere etterlevelsen. I den tredje var kravene til hva som ble definert som høy etterlevelse svært lave (20).

Graden av etterlevelse falt med tiden. I studien med seks måneders oppfølgingstid sank antall dager med korrekt inntak av legemidlet med 2,5 prosentpoeng per måned hos dem som fullførte (17). Hos den tredelen av pasientene som i løpet av studieperioden helt sluttet å ta legemidlet, sank etterlevelsen tre ganger så raskt. Andre studier har vist at så mange som halvparten av pasienter med depresjon har sluttet å ta sitt antidepressive

Tabell 2 Faktorer som er assosiert med nedsatt etterlevelse og forslag til tiltak for å øke etterlevelsen $(2-5,17,21)$

\section{Faktor assosiert med nedsatt etterlevelse}

Dosering mer enn én gang daglig

Komplekse behandlingsregimer

Forglemmelser, nedsatt kognitiv funksjon

Samtidig depresjon

Mangelfull innsikt i sykdommen

Mangelfull tro på behandlingen

Frykt for bivirkninger

Forekomst av bivirkninger

Utilstrekkelig oppfølging

Praktiske problemer (vanskeligheter med å åpne pakningen, store tabletter, vond smak etc.)

\section{Forslag til tiltak}

Dosering én gang daglig hvis mulig, bruke depottabletter

Seponere unødvendige legemidler, bruke kombinasjonspreparater hvis mulig

Bruke doseringshjelpemidler som dosett, inngå allianse med pårørende, involvere hjemmetjenesten

Som over, behandle depresjonen

Informasjon, motiverende samtale, inngå allianse med pårørende, øke konsultasjonsfrekvensen

Fange opp pasientens signaler, informere/ motivere, inngå allianse med pårørende

Fange opp pasientens signaler, informere, dosere slik at risikoen for bivirkninger reduseres (se under)

Starte med lave doser, trappe opp langsomt, følge opp, ev. bytte legemiddel

Kortere ventetider, økt tilgjengelighet, hyppigere kontroller

Bytte til preparat/formulering som er lettere å håndtere, se til at pasienten kan få hjelp fra andre middel tre måneder etter behandlingsstart (26). Ved langtidsbehandling er høy etterlevelse etter ett år assosiert med høy etterlevelse også senere: I studien av pasienter med schizofreni hadde $81 \%$ fortsatt høy etterlevelse etter to år og $69 \%$ etter tre år (18). Av dem med lav etterlevelse etter ett år var det kun $39 \%$ og $37 \%$ som hadde høy etterlevelse etter to år og tre år $(p<0,001)$.

I to av studiene var høy alder assosiert med høy etterlevelse $(18,19)$. I en studie var etterlevelsen høyere like etter legebesøk (17). Det var intet mønster ut fra diagnose i de studiene vi inkluderte, men i en oversiktsartikkel som inkluderte 24 originalarbeider publisert i perioden 1975-1996, fant man at i gjennomsnitt hadde $65 \%$ av dem som ble behandlet med antidepressiver høy etterlevelse, mot $58 \%$ av dem som ble behandlet med antipsykotika (26).

I begge studiene der man så på risikoen for sykehusinnleggelse, var denne 2-3 ganger høyere hos pasienter med lav etterlevelse $(18,20)$.

\section{Antibiotika}

Resultatene fra de to inkluderte studiene (21, 22) presenteres i detalj i e-tabell 1. Andelen pasienter med høy etterlevelse var $41 \%$ (21) og $70 \%$ (22). I studien der man fant den laveste etterlevelsen var kravene strenge, da dosene også måtte tas til riktig tid, mens i den andre studien ble høy etterlevelse kun definert som funn av legemiddel i én enkelt urinprøve. I begge studiene fant man at lengre behandlingstid var forbundet med lavere etterlevelse. I den ene studien tok $92 \%$ av pasientene minst $80 \%$ av tablettene ved tre dagers behandling, sammenliknet med $77 \%$ ved sju dagers behandling og $69 \%$ ved ti dagers behandling $(\mathrm{p}<0,01)$ (21). I den andre studien hadde 75-79\% høy etterlevelse ved en behandlingsperiode på sju dager eller mindre, sammenliknet med $63-65 \%$ ved behandling på over sju dager $(p=0,014)(22)$. Én daglig dose ga høyere etterlevelse enn flere doser om dagen (21). Det var ingen signifikante forskjeller i etterlevelse ut fra alder, kjønn, sivilstatus, utdanningsnivå eller andre samtidige sykdommer.

Disse funnene er i stor grad i overensstemmelse med de resultatene som presenteres i en oversiktsartikkel om etterlevelse ved antibiotikabruk mot luftveisinfeksjon (27). I denne artikkelen pekes det også på at det er en ikke ubetydelig forskjell mellom to og tre daglige doser, og at det ved dosering tre ganger daglig som oftest er den andre dosen som ikke blir tatt.

\section{Analgetika}

Resultatene fra de tre inkluderte studiene (23-25) presenteres i detalj i e-tabell 1. Alle tre omhandler etterlevelse ved behandling av smerte hos kreftpasienter. I to av studiene hadde man ikke definert noen grense for høy etterlevelse, men man fant at $87-89 \%$ av 
dosene ble tatt $(24,25)$. Andelen dager hvor tablettene ble tatt til rett tid var derimot $53 \%$ (24). I den tredje studien fant man at $41 \%$ av pasientene oppfylte forhåndsdefinerte kriterier for høy etterlevelse (23). Alder, kjønn, utdanningsnivå, sivilstatus eller hvorvidt pasientene var i arbeid eller ikke påvirket ikke etterlevelsen. Oppfølgingstiden var kort i alle studiene, fra én til fem uker, noe som kan forklare at man ikke kunne påvise noe fall i etterlevelse med tiden.

\section{Diskusjon}

Vår gjennomgang viser at det er et betydelig sprik i metodebruk, design og definisjoner i studier av medikamentetterlevelse. Dermed blir tallene ofte ikke sammenliknbare. Studiene viser likevel et mønster når det gjelder hvilke faktorer som påvirker etterlevelsen. De to viktigste forholdene ser ut til å være diagnose og tid fra behandlingsstart.

Siden vi ikke har gjort en systematisk gjennomgang av alle relevante artikler på området, kan vi ikke utelukke at inklusjon av andre studier ville ha gitt resultater som avviker fra dem vi presenterer her. Imidlertid støttes våre resultater av tidligere oversiktsartikler på de områdene der dette er tilgjengelig $(2,3,26,27)$.

Andelen med høy etterlevelse ved de tilstandene vi har beskrevet varierte mye. Når vi tar hensyn til at det er brukt ulik design og at oppfølgingstiden har variert mellom de forskjellige studiene, ser det ut til at etterlevelsen var høyest hos dem som brukte analgetika, antibiotika, antiepileptika og perorale antidiabetika, og lavest hos dem som brukte antihypertensiver, psykofarmaka og statiner. Denne variasjonen kan skyldes faktorer som hvor mye symptomer tilstanden gir, hvor alvorlig den oppleves og varigheten av behandlingen.

Ved forebyggende behandling av symptomfrie tilstander som hypertensjon og forhøyede kolesterolnivåer var andelen med høy etterlevelse $30-60 \%$, mens den ved behandling av tilstander som gir symptomer (smertefulle sykdommer og infeksjonssykdommer) lå i området $60-90 \%$. Det ser altså ut til at påminnelser i form av symptomer øker etterlevelsen. Imidlertid er det også viktig å se på oppfølgingstiden, som varierte fra få uker (analgetika/antibiotika) til 1-5 år (antihypertensiver/statiner). Siden etterlevelsen generelt sett er fallende over tid, kan forskjeller i oppfølgingstid være med på å forklare hvorfor den var høyere ved behandling av smerter/ infeksjoner enn ved forebygging av sykdom. Vi mangler data som viser hva etterlevelsen er for antihypertensiver og statiner få uker etter behandlingsstart.

Når vi tar hensyn til oppfølgingstid, ser det ut til at etterlevelsen ved psykiske sykdommer er lavere enn etterlevelsen ved somatiske sykdommer som diabetes og epilepsi. Det kan skyldes de psykiske sykdommenes natur. Til sykdomsbildet ved depresjon hører likegyldighet, noe som kan bidra til lavere etterlevelse. Det er også eksempler på at pasienter med depresjon i sykehistorien har lavere etterlevelse ved bruk av legemidler beregnet på andre tilstander, som diabetes og høye kolesterolnivåer $(3,15)$. Ved schizofreni er realitetsbrist en del av sykdomsbildet, noe som kan vanskeliggjøre etterlevelsen. På den annen side er ikke etterlevelsen generelt sett lavere ved depresjon/schizofreni enn ved hypertensjon/høye kolesterolnivåer.

En rekke faktorer har vist seg å være modifiserende på graden av etterlevelse (tab 2) $(2-5,17,21)$. Et av de tydeligste funnene er at dosering to ganger per dag gir lavere etterlevelse enn dosering én gang daglig og at etterlevelsen reduseres ytterligere med økende antall daglige inntak $(3-5,21)$. Det er også en tendens til at behandling med flere legemidler mot samme sykdom (polyfarmasi) gir lavere etterlevelse. Imidlertid har ikke dette vært entydig. For eksempel fant man i en studie at etterlevelsen ved epilepsi var høyere hos dem som tok mer enn ett legemiddel (10). Årsaken til dette kan være at pasienter i denne gruppen har en mer alvorlig sykdom og dermed økt forståelse for viktigheten av å ta legemidlene. I tillegg kan det tenkes at disse pasientene følges opp med hyppigere kontroller, noe som også gir økt etterlevelse (2). Overgang fra polyfarmasi til kombinasjonspreparater øker etterlevelsen (28).

I noen studier har man funnet at etterlevelsen er høyest kort tid før og like etter legebesøk. I disse periodene er det naturlig at pasienten har økt oppmerksomhet omkring behandlingen og kanskje også økt motivasjon for å fortsette med den $(2,17)$. En konsekvens av dette er at hyppige kontroller vil kunne øke etterlevelsen.

Også administrasjonsformen kan ha betydning for etterlevelsen. For eksempel var det $i$ en studie om inntak av antibiotika hos småbarn fortsatt $82 \%$ som brukte legemidlet etter fire dager når det var gitt som mikstur, mot bare $55 \%$ ved bruk av tabletter (27).

Ved diabetes, epilepsi og psykiske sykdommer øker risikoen for sykehusinnleggelse ved lav etterlevelse $(6,8,9,18,20)$. I en av studiene der man undersøkte etterlevelsen ved bruk av antibiotika, fant man imidlertid at av dem med lav og av dem med høy etterlevelse ble en like stor andel vurdert som bedre eller friske av legen siste behandlingsdag (22). Slike forskjeller kan henge sammen med indikasjon for behandlingen hvis indikasjonen er sterk og effekten av behandlingen god, vil naturligvis høy etterlevelse være langt viktigere enn hvis indikasjonen er tvilsom og effekten beskjeden.

I en metaanalyse av 21 originalstudier der sammenhengen mellom etterlevelse og død ved i hovedsak hivinfeksjon og hjerteinfarkt ble beskrevet, fant man at høy etterlevelse var forbundet med lavere risiko for død (OR 0,$56 ; 95 \%$ KI $0,50-0,63$ ) (29). Imidlertid fant man en tilsvarende effekt også hos dem som hadde fått placebo. Dette kan tyde på at pasienter med høy etterlevelse i større grad også følger andre råd om helse og sykdom, for eksempel når det gjelder fysisk aktivitet, kosthold og røykestopp. Dette fenomenet kalles gjerne «healthy adherer effect» (29). Dermed ser det ut til at gunstige effekter på sykelighet og dødelighet hos personer med høy etterlevelse ikke bare skyldes legemidlenes iboende farmakologiske egenskaper.

Det har vært pekt på at lav etterlevelse er en viktigere årsak til mangelfull sykdomskontroll enn at legemidlene som sådanne ikke virker (3). Derfor er det viktig å kartlegge graden av etterlevelse før det eventuelt gjøres doseringsendringer eller byttes til et annet legemiddel. En enkel og praktisk måte å gjøre dette på er å spørre på en åpen og fordomsfri måte hvor ofte pasienten ikke tar legemidlet. Måten man spør på er viktig. Spørsmål av typen «Jeg vet at det er vanskelig å huske å ta medisinen hver dag. Hvor ofte hender det at du glemmer å ta legemidlet ditt?» kan anbefales. Det er samtidig viktig at legen prøver å fange opp hvorvidt pasienten ønsker å ta legemidlet og om det er praktiske problemer forbundet med inntaket.

En måte å få høyere etterlevelse på kan være å bedre informasjonen om hensikten med behandlingen. Tilrettelegging av praktiske forhold, forenkling av doseringen og tettere oppfølging vil også kunne gi bedre etterlevelse. Oppnår man ikke høy etterlevelse ved hjelp av de nevnte metodene, kan man forsøke å endre behandlingen. Uavhengig av hvilken metode man velger, er god kommunikasjon mellom pasient og lege en nøkkelfaktor.

e-tab 1 finnes kun i Tidsskriftets nettutgave.

\section{Ingrid Hov (f. 1985)}

er turnuslege.

Ingen oppgitte interessekonflikter.

\section{Margunn Bjartnes (f. 1984)}

er turnuslege.

Ingen oppgitte interessekonflikter.

\section{Lars Slørdal (f. 1955)}

er dr. med., professor i farmakologi ved Norges teknisk-naturvitenskapelige universitet og overlege ved Avdeling for klinisk farmakolog ved St. Olavs hospital.

Ingen oppgitte interessekonflikter.

\section{Olav Spigset (f. 1963)}

er dr.med., overlege ved Avdeling for klinisk farmakologi, St. Olavs hospital, og professor i klinisk farmakologi ved Norges teknisk-naturvitenskapelige universitet.

Ingen oppgitte interessekonflikter. 


\section{Litteratur}

1. Bjartnes M, Hov I. Tar pasienter legemidler som forskrevet? Hovedoppgave. Trondheim: Det medisinske fakultet, Norges teknisk-naturvitenskapelige universitet, 2010.

2. Osterberg L, Blaschke T. Adherence to medication. N Engl J Med 2005; 353: 487-97.

3. Cramer JA. A systematic review of adherence with medications for diabetes. Diabetes Care 2004; 27: $1218-24$.

4. Hertz RP, Unger AN, Lustik MB. Adherence with pharmacotherapy for type 2 diabetes: a retrospective cohort study of adults with employersponsored health insurance. Clin Ther 2005; 27. 1064-73.

5. Donnan PT, MacDonald TM, Morris AD. Adherence to prescribed oral hypoglycaemic medication in a population of patients with Type 2 diabetes: a retrospective cohort study. Diabet Med 2002 19: $279-84$

6. Ho PM, Rumsfeld JS, Masoudi FA et al. Effect of medication nonadherence on hospitalization and mortality among patients with diabetes mellitus. Arch Intern Med 2006; 166: 1836-41.

7. Balkrishnan R, Rajagopalan R, Camacho FT et al. Predictors of medication adherence and associated health care costs in an older population with type 2 diabetes mellitus: a longitudinal cohort study. Clin Ther 2003; 25: 2958-71.

8. Faught E, Duh MS, Weiner JR et al. Nonadherence to antiepileptic drugs and increased mortality: findings from the RANSOM Study. Neurology 2008; 71: $1572-8$.

9. Davis KL, Candrilli SD, Edin HM. Prevalence and cost of nonadherence with antiepileptic drugs in an adult managed care population. Epilepsia 2008; 49: 446-54.

10. Buck D, Jacoby A, Baker GA et al. Factors influencing compliance with antiepileptic drug regimes. Seizure 1997; 6: 87-93.

11. Monane M, Bohn RL, Gurwitz JH et al. Compliance with antihypertensive therapy among elderly Medi- caid enrollees: the roles of age, gender, and race. Am J Public Health 1996; 86: 1805-8

12. Ren XS, Kazis LE, Lee A et al. Identifying patient and physician characteristics that affect compliance with antihypertensive medications. J Clin Pharm Ther 2002; 27: 47-56.

13. Nabi H, Vahtera J, Singh-Manoux A et al. Do psychological attributes matter for adherence to anti hypertensive medication? The Finnish Public Sector Cohort Study. J Hypertens 2008; 26: 2236-43.

14. Jackevicius CA, Mamdani M, Tu JV. Adherence with statin therapy in elderly patients with and without acute coronary syndromes. JAMA 2002; 288: $462-7$.

15. Benner JS, Glynn RJ, Mogun H et al. Long-term persistence in use of statin therapy in elderly patients. JAMA 2002; 288: 455-61.

16. Ellis JJ, Erickson SR, Stevenson JG et al. Suboptimal statin adherence and discontinuation in primary and secondary prevention populations. J Gen Intern Med 2004; 19: 638-45.

17. Demyttenaere K, Adelin A, Patrick M et al. Sixmonth compliance with antidepressant medication in the treatment of major depressive disorder Int Clin Psychopharmacol 2008; 23: 36-42.

18. Ascher-Svanum H, Faries DE, Zhu B et al. Medication adherence and long-term functional outcomes in the treatment of schizophrenia in usual care. J Clin Psychiatry 2006; 67: 453-60.

19. Akincigil A, Bowblis JR, Levin C et al. Adherence to antidepressant treatment among privately insured patients diagnosed with depression. Med Care 2007: 45: 363-9.

20. Svarstad BL, Shireman TI, Sweeney JK. Using drug claims data to assess the relationship of medication adherence with hospitalization and costs. Psychiatr Serv 2001; 52: 805-11.

21. Llor C, Sierra N, Hernández S et al. The higher the number of daily doses of antibiotic treatment in lower respiratory tract infection the worse the compliance. J Antimicrob Chemother 2009; 63: 396-9.
22. Hoppe JE, Blumenstock G, Grotz W et al. Compliance of German pediatric patients with oral antibiotic therapy: results of a nationwide survey. Pediatr Infect Dis J 1999; 18: 1085-91.

23. Valeberg BT, Miaskowski C. Hanestad BR et al. Prevalence rates for and predictors of selfreported adherence of oncology outpatients with analgesic medications. Clin J Pain 2008; 24: 627-36.

24. Oldenmenger WH, Echteld MA, de Wit R et al. Analgesic adherence measurement in cancer patients: comparison between electronic monitoring and diary. J Pain Symptom Manage 2007; 34: 639-47.

25. Miaskowski C, Dodd MJ, West $C$ et al. Lack of adherence with the analgesic regimen: a significant barrier to effective cancer pain management. J Clin Oncol 2001: 19: 4275-9.

26. Cramer JA, Rosenheck R. Compliance with medication regimens for mental and physical disorders. Psychiatr Serv 1998; 49: 196-201.

27. Kardas P. Patient compliance with antibiotic treatment for respiratory tract infections. J Antimicrob Chemother 2002; 49: 897-903.

28. Bangalore S, Kamalakkannan G, Parkar S et al. Fixed-dose combinations improve medication compliance: a meta-analysis. Am J Med 2007; 120: $713-9$

29. Simpson SH, Eurich DT, Majumdar SR et al. A meta-analysis of the association between adherence to drug therapy and mortality. BMJ 2006; 333: 15 .

Mottatt 1.3. 2011, første revisjon innsendt 16.5 2011, godkjent 15.12. 2011. Medisinsk redaktør Mette Sagsveen. 